\title{
Kinetic, isotherm and thermodynamics investigation on adsorption of divalent copper using agro-waste biomaterials, Musa acuminata, Casuarina equisetifolia L. and Sorghum bicolor
}

\author{
Ramya Prasanthi Mokkapati ${ }^{1}$, Jayasravanthi Mokkapati ${ }^{2}$, Venkata Nadh Ratnakaram ${ }^{3 *}$ \\ ${ }^{1}$ Acharya Nagarjuna University, Department of Chemistry, ANUCET, Guntur - 522510, India \\ ${ }^{2}$ Acharya Nagarjuna University, Department of Biotechnology, Guntur - 522510, India \\ ${ }^{3}$ GITAM University - Bengaluru, Karnataka - 561203, India \\ "Corresponding author: e-mail: doctornadh@yahoo.co.in
}

\begin{abstract}
Three novel and distinct agricultural waste materials, viz., Casuarinas fruit powder (CFP), sorghum stem powder (SSP) and banana stem powder (BSP) were used as low cost adsorbents for the removal of toxic copper(II) from aqueous solutions. Acid treated adsorbents were characterized by SEM, EDX and FTIR. Different factors effecting adsorption capacity were analyzed and the efficiency order was BSP $>$ SSP $>$ CFP. Based on the extent of compatibility to Freundlich/Langmuir/D-R/Temkin adsorption isotherm and different models (pseudo-first and second order, Boyd, Weber's and Elovich), chemisorption primarily involved in the case of CFP and SSP, whereas, simultaneous occurrence of chemisorption and physisorption was proposed in the case of BSP. Based on the observations, it was proposed that three kinetic stages involve in adsorption process viz., diffusion of sorbate to sorbent, intra particle diffusion and then establishment of equilibrium. These adsorbents have promising role towards removal of $\mathrm{Cu}(\mathrm{II})$ from industrial wastewater to contribute environmental protection.
\end{abstract}

Keywords: banana bunch-stem powder, casuarinas fruit powder, sorghum stem powder, removal, copper, adsorption.

\section{INTRODUCTION}

Technological advancements and improved industrialization in this modern era lead to the increased release of heavy metal ions in to the water bodies like rivers, lakes etc $^{1}$. Copper is non-biodegradable and its accumulation in ecological system can cause harmful effects to plants, human and animals ${ }^{2}$. Even though trace amounts of copper is nutritious, the higher concentrations exceeding the limit $1.5 \mathrm{mg} \mathrm{L}^{-1}$ can cause many severe diseases such as liver and kidney damage, intestinal distress and stomach ailments, cancer, nausea, vomiting, headache, diarrhea, respiratory difficulties ${ }^{3}$. Excess of copper (II) leads to different types of cancers since it can be deposited in the brain, skin, liver and pancreas, and finally leading to death ${ }^{4,5}$. In addition, $\mathrm{Cu}(\mathrm{II})$ in acidic $\mathrm{pH}$ can cause toxicological concerns to fish and other aquatic life even in trace quantities ${ }^{6}$.

The conventional treatment techniques for copper removal from aqueous solutions include chemical precipitation, ion exchange, membrane filtration, solvent extraction, phyto extraction, ultra filtration, reverse osmosis, adsorption etc. In addition, a number of non-conventional strategies involving the use of lignocellulosic materials ${ }^{7}$, inorganic clay materials ${ }^{8}$, biopolymers ${ }^{9}$ and synthetic polymeric hydrogels ${ }^{\mathbf{1 0}}$ have also been reported in the recent past. However, these processes used for the separation of metal from contaminated water are cumbersome and involve high cost consumption materials, for example, activated carbon for adsorption ${ }^{11}$. Hence, among all water-treatment methods described, biosorption is a highly preferred technique due to its efficiency, easy handling and economic bulk availability of adsorbents ${ }^{12-14}$. Particularly, the adsorbent materials from agricultural origin have high affinity for $\mathrm{Cu}$ (II) due to their various functional groups including carboxyl, amide and hydroxyl group, etc. which are often ideal because of their susceptibility to chemical modification and mono to multilayer adsorption behavior for better performance $^{15}$.

Therefore, the present study is focusing on the use of three novel chemically modified agricultural waste materials viz., Musa acuminate (banana bunch stem powder - BSP), Casuarina equisetifolia L. (casuarinas fruit powder - CFP) and Sorghum bicolor (sorghum stem powder - SSP) for effective removal of $\mathrm{Cu}$ (II) from aqueous solutions. A comparative analysis throughout the study using these three adsorbents can give better understanding of the adsorption process in terms of efficiency to remove copper metal ion from synthetic aqueous solutions.

\section{EXPERIMENTAL}

Raw materials such as casuarinas fruit, sorghum stem and banana bunch-stem for the preparation of adsorbents are available abundantly in nature. They were cleaned with distilled water. To reduce the organic leaching and prevent mould growth during batch sorption the raw materials were washed with $2 \%$ formaldehyde solution ${ }^{16}$ and completely air dried. The dried material was fine powdered and sieved through standard sieves of particle size $0.3 \mathrm{~mm}$ to $1.0 \mathrm{~mm}$. In general, the adsorption capacity is improved by modifying the nature of biosorbent by different methods such as acid and alkali modification, oxidation, and chemical graft ${ }^{17,18}$. These techniques activate the sorbent by increasing active surface area and improving chemical reactivity by formation of surface functional groups which helps to chemically bond with the heavy metals. Hence, the finest powders of casuarinas fruit (CFP) and sorghum stem (SSP) were treated (soaked for $24 \mathrm{~h}$ at room temperature) with $1 \mathrm{~N}_{2} \mathrm{SO}_{4}$ and banana bunch-stem (BSP) was treated with $1 \mathrm{~N}^{\mathrm{HNO}_{3}}$. The samples were washed with distilled water, oven dried 
and cooled back to room temperature. The bio-sorbent materials were stored in clean air tight containers and used in the adsorption experiments. The preliminary studies shows that the removal capacity of these treated adsorbents is higher by about $30 \%$ compared to those of untreated adsorbents. Hence, treated samples were used throughout the study.

All the chemicals used were of analytical grade. The standard copper stock solution of $1000 \mathrm{mg} \mathrm{L}^{-1}$ concentration certified for atomic absorption spectroscopy was obtained from Loba Chemie Laboratory Reagents and Fine Chemicals, India. Working copper solution was prepared in bulk with deionised water and used for the adsorption studies. The initial $\mathrm{Cu}$ (II) concentration of the untreated sample was $36 \mathrm{mg} \mathrm{L}^{-1}$. The typical $\mathrm{pH}$ of the experiments was about 5 , and it was adjusted to the desired value by the addition of few drops of $0.1 \mathrm{M} \mathrm{HCl}$ or $0.1 \mathrm{M} \mathrm{NaOH}$. Blank experiments were carried out to study the adsorption of copper on the walls of batch reactor and found negligible.

\section{Instrumentation}

The physical-chemical characterization of adsorbents was performed by Scanning Electron Microscopy (SEM) coupled to Energy-Dispersive X ray spectroscopy (EDX) [FEI Quanta FEG 200 - High Resolution Scanning Electron Microscope] which also allows the identification and quantification of the metal ions of the adsorbents. The FT-IR spectra were performed using Bruker, ALPHA-T to identify the active functional groups responsible for the adsorption.

\section{Batch adsorption studies}

The experiments were performed in batch process using BSP, CFP and SSP at room temperature in $250 \mathrm{ml}$ conical flask containing $50 \mathrm{ml}$ of reaction mixture. While observing the effect of each parameter, the values of other parameters were kept constant. The removal efficiency of each adsorbent with respect to different parameters like adsorbent dose $[2,4,6,8,10,15$ and $20 \mathrm{~g} \mathrm{~L}^{-1}$ ], time [30, 60, 90, 120, 150, 180 and $210 \mathrm{~min}$ ], $\mathrm{pH}\left[2,3,4\right.$ and 5], temperature $\left[30,40,50,60\right.$ and $\left.70^{\circ} \mathrm{C}\right]$ and initial $\mathrm{Cu}(\mathrm{II})$ concentration $[35,50,100,150$ and $\left.200 \mathrm{mg} \mathrm{L}^{-1}\right]$ was determined in individual experiments. In each experiment, the metal ion solution equilibrated with adsorbent were withdrawn, centrifuged and the final $\mathrm{Cu}$ (II) concentration were measured by atomic absorption spectroscopy ${ }^{19}$. The experiment was repeated thrice and average results have been reported. The relative errors in the experimental results were about $5 \%$.

The adsorption capacity was determined by the following equation:

$\mathrm{q}_{\mathrm{e}}=\left[\left(\mathrm{C}_{\mathrm{o}}-\mathrm{C}_{\mathrm{e}}\right) * \mathrm{~V}\right] / \mathrm{W}$

where, $\mathrm{C}_{\mathrm{o}}$ is the initial concentration of $\mathrm{Cu}(\mathrm{II})$ in solution, $\mathrm{C}_{\mathrm{e}}$ is the final concentration of $\mathrm{Cu}(\mathrm{II})$ in solution after adsorption, $\mathrm{q}_{\mathrm{e}}\left(\mathrm{mg} \mathrm{g}^{-1}\right)$ is the adsorption capacity of the adsorbent at equilibrium, $\mathrm{V}(\mathrm{L})$ is the volume of suspension, and $\mathrm{W}(\mathrm{g})$ is the mass of adsorbent.

\section{RESULTS AND DISCUSSION}

\section{SEM, EDX and FT-IR studies}

The visible observation of the surface texture and porosity of the samples using scanning electron microscopy (SEM) gives better understanding of the nature of adsorption process and was given in Figure 1. Rough surface with some pore formation were visualized before adsorption as an indication of large surface areas (Fig. 1a) capable of high adsorption, whereas, a smooth surface covering of the pores can be observed after adsorption (Fig. 1b). EDX studies were carried out to determine the chemical composition of adsorbents (wt\% of elements). Before adsorption: BSP: C-58.19, O-41.40, Fe-0.11, $\mathrm{Cu}-0.00$; SSP: C-55.46, O-38.33, Fe-0.13, Zn-0.02, $\mathrm{Cu}-0.02$; CFP: C-62.70, O-36.23, Fe-0.17, Cu-0.00; After adsorption: BSP: C-54.21, O-42.87, Fe-0.17, Cu-0.92; SSP: C-46.69, O-37.60, Fe-02.17, Zn-0.15, Cu-0.28; CFP: C-62.95, O-34.98, Fe-0.17, Cu-0.23. Successful loading of copper on the surface of sorbents was confirmed with EDX spectra of biosorbents, both prior and after batch process. In all the adsorbents, presence of stretching for $\mathrm{C}-\mathrm{O}, \mathrm{C}=\mathrm{O}$ and aliphatic $\mathrm{C}-\mathrm{H}$ can be confirmed from peaks in the range of $1023-1039 \mathrm{~cm}^{-1}, 1614-1689 \mathrm{~cm}^{-1}$ and $2917-2920 \mathrm{~cm}^{-1}$ respectively. But, additional peaks in CFP above $3000 \mathrm{~cm}^{-1}$ indicate the $=\mathrm{C}$-H stretching and further $\mathrm{C}=\mathrm{C}$ stretching can be observed from peaks in the range of $1450-1550 \mathrm{~cm}^{-1}$. Broad peaks in the range of $3305-3320 \mathrm{~cm}^{-1}$ indicate the presence of carboxylic acid groups in SSP and BSP, whereas, dominant sharp peak at $3737 \mathrm{~cm}^{-1}$ indicates phenolic groups in CFP (Fig. 2). Based on the FTIR bands, adsorption of copper ions can be partly attributed to electrostatic attraction ${ }^{20}$.
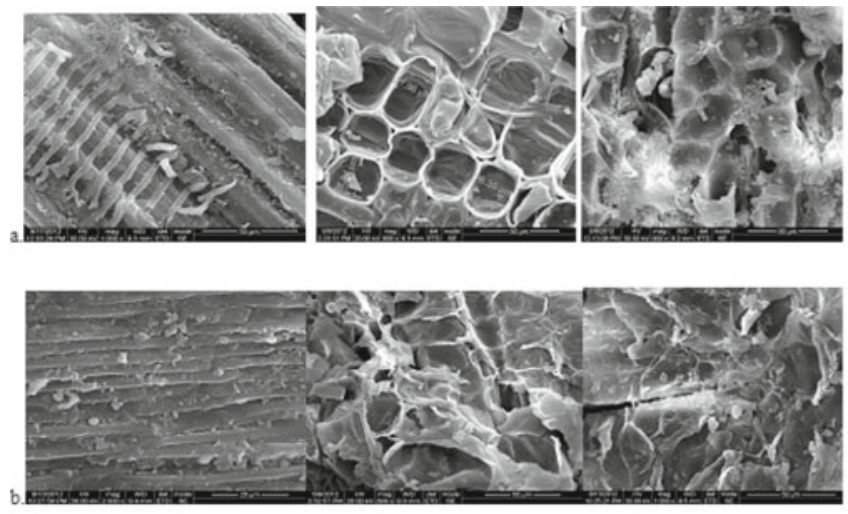

Figure 1. SEM images of BSP, SSP and CFP (a) Before adsorption and (b) After adsorption of $\mathrm{Cu}$ (II) respectively

EDX and FT-IR observations correlate with the compositions of BSP [holocellulose, cellulose, lignin, pectin] ${ }^{\mathbf{2 1}}$, SSP [cellulose, hemicelluloses, lignin, cutin, silica] ${ }^{22}$, and CFP $[\alpha$-pinene, benzaldehyde, 1,8 cineole, furanoid, $\alpha$-campholenal, 4-terpineol, $\alpha$-terpineol, $\alpha$-terpinyl acetate, spathulenol, caryophyllene-oxide, guaiol $]^{23}$. The presence of functional groups like acid, alcohol and amine are evident from these studies. Protons of phenols/ alcohols and carboxylic acid groups in these biosorbent facilitate them for ions getting exchanged during the adsorption process. Hydroxyl groups in these biopolymers may function as donors. Hence the de-protonation of hydroxyl groups can be involved in the co-ordination 

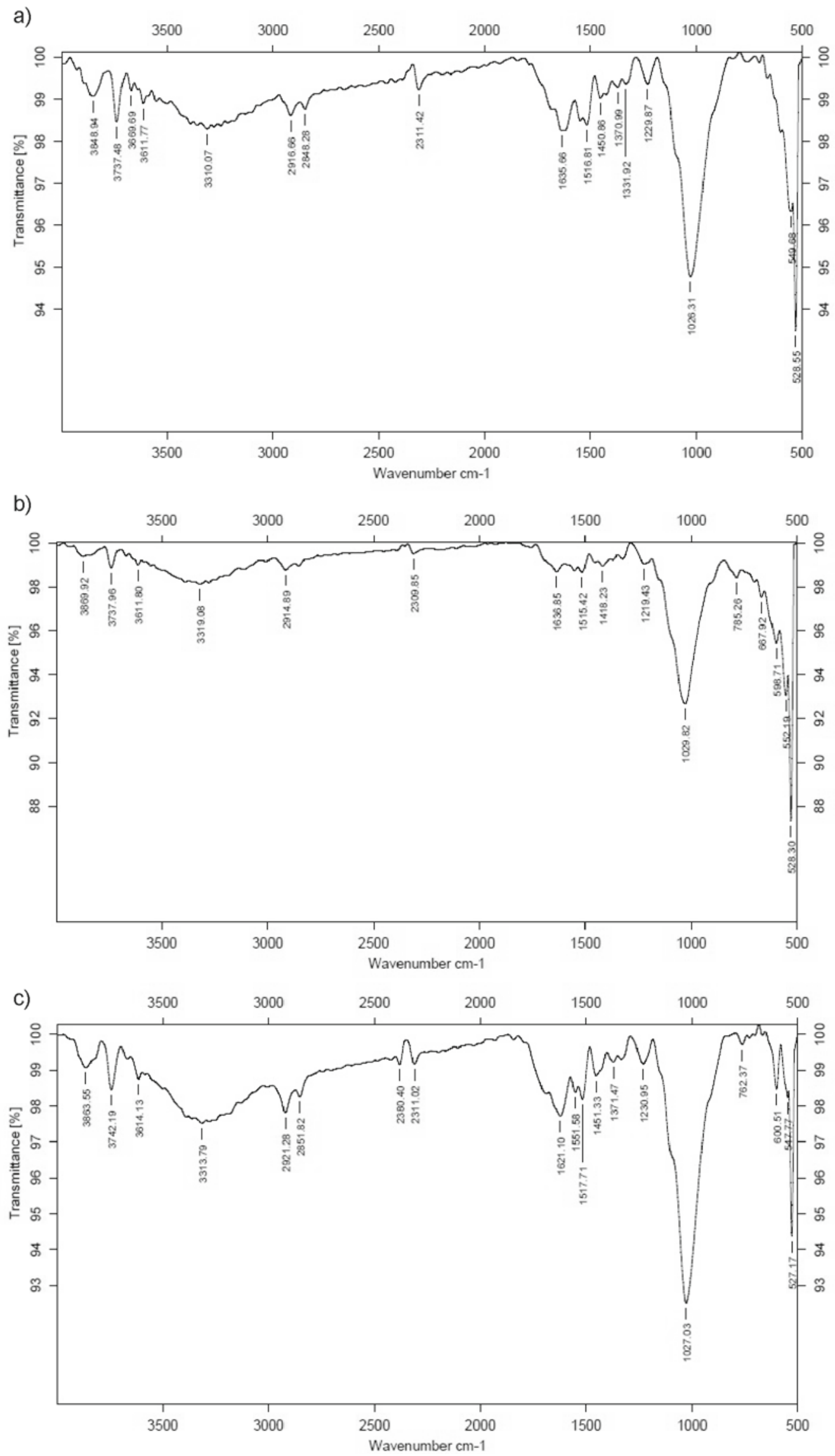

Figure 2. FTIR spectra of acid treated biosorbents (a) BSP, (b) SSP and (c) CFP before adsorption

with metal ions ${ }^{24}$. Moreover, presence of more number of peaks in CFP compared to SSP can be explained based on presence of good number of phytochemicals as mentioned above.
Studies on effect of contact time and adsorption kinetics

To better understand the $\mathrm{Cu}$ (II) sorption characteristics by the three adsorbents (BSP, SSP and CFP), both kinetic and equilibrium models were used to describe the data. Change in $\mathrm{Cu}(\mathrm{II})$ concentrations over time was investigated at each $30 \mathrm{~min}$ interval in contact time till 
210 mins, while other parameters were kept constant (Fig. 3). An increase in contact period between adsorbent and $\mathrm{Cu}(\mathrm{II})$ ions increases the adsorption of metal ion as because more time familiarizes the metal ion to bond with the adsorbent ${ }^{25,26}$. The results revealed that the equilibrium was established at a point of $180 \mathrm{~min}$ in case of BSP and $120 \mathrm{~min}$ in case of SSP and CFP as adsorbents. The better performance of these adsorbents compared to the earlier used adsorbents in terms of optimum time required is manifested in the present case because it is $6 \mathrm{~h}$ using garden grass ${ }^{13}, 25 \mathrm{~h}$ using fish bones ${ }^{27}, 36 \mathrm{~h}$ using porous geo polymeric spheres ${ }^{28}$.

From Figure 3, it is clear that metal sorption follow three step sorption mechanism. During the initial rapid and quantitatively predominant step, large number of sites are available for uptake of $\mathrm{Cu}$ (II) metal ions on the adsorbents which permits to overcome all the external mass transfer resistances and occupying the active sites on the biosorbent with higher affinity through bonding with the functional groups on sorbent ${ }^{14}$. During the second slower and quantitatively insignificant step, the diffusion of $\mathrm{Cu}$ (II) into the deeper pores creates repulsive forces between the $\mathrm{Cu}(\mathrm{II})$ on the solid and the aqueous phases and the existence of different sorption mechanisms might hamper the adsorption process ${ }^{2}$ leading to slower adsorption rate. During the final equilibrium phase, the sorption process ceases due to unavailability of active sites on biosorbents to be occupied by the metal ions or the difficulties in adsorbate-adsorbent interactions.

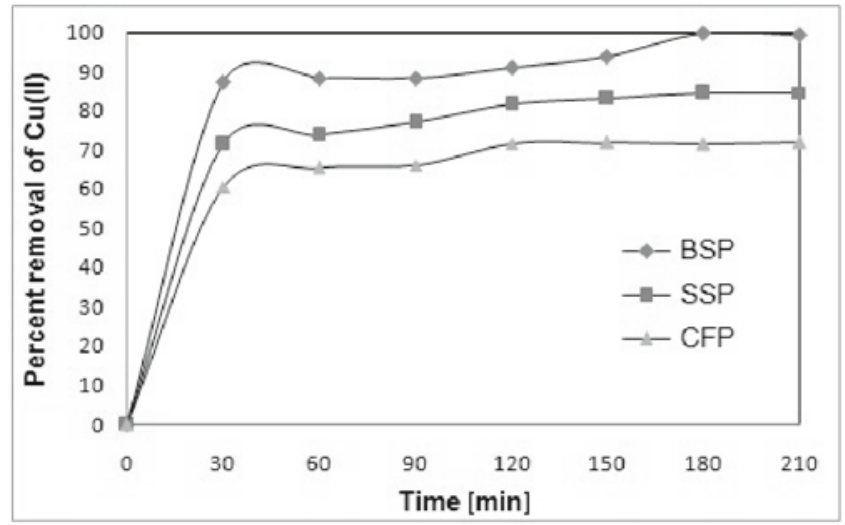

Figure 3. Effect of contact time on $\mathrm{Cu}(\mathrm{II})$ sorption, at $5 \mathrm{pH}$, $36 \mathrm{mg} \mathrm{L}^{-1} \mathrm{Cu}(\mathrm{II}), 200 \mathrm{rpm}, 15 \mathrm{~g} \mathrm{~L}^{-1} \mathrm{SSP}$ and $5 \mathrm{~g} \mathrm{~L}^{-1}$ CFP and BSP and RT

Further research on kinetics of adsorption was carried out by employing pseudo first order (Eq. 2 ) $^{29}$ and pseudo second order (Eq. 3$)^{30}$ kinetic equations to examine the mechanism of $\mathrm{Cu}(\mathrm{II})$ adsorption (Fig. 4).

$\ln \left(\mathrm{q}_{\mathrm{e}}-\mathrm{q}_{\mathrm{t}}\right)=\ln \mathrm{q}_{\mathrm{e}}-\mathrm{k}_{1} \mathrm{t}$

$\mathrm{t} / \mathrm{q}=\left(1 / \mathrm{k}_{2} \mathrm{q}_{\mathrm{e}}^{2}\right)+\left(\mathrm{t} / \mathrm{q}_{\mathrm{e}}\right)$

Where $\mathrm{q}_{\mathrm{t}}$ and $\mathrm{q}_{\mathrm{e}}\left(\mathrm{mg} \mathrm{g}^{-1}\right)$ are the amounts of copper adsorbed on adsorbent at time $\mathrm{t}$ and at equilibrium, respectively, $\mathrm{k}_{1}$ and $\mathrm{k}_{2}$ are the corresponding pseudo

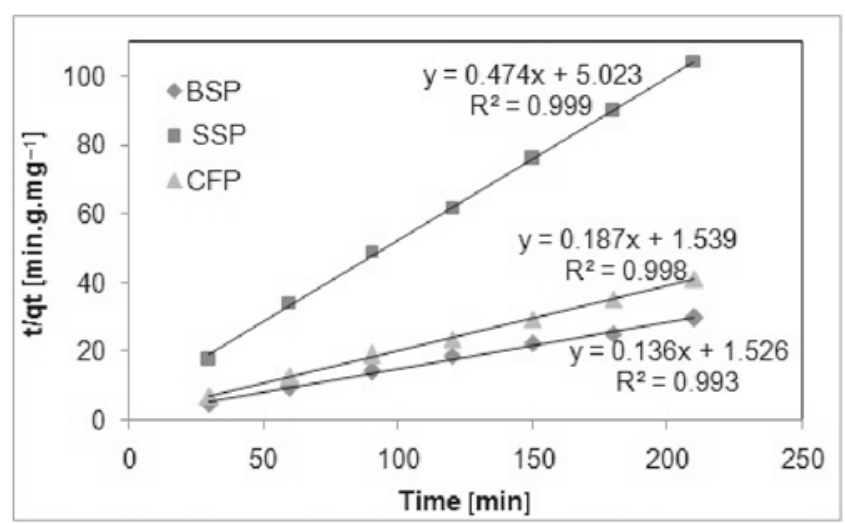

Figure 4. Pseudo second order adsorption model for the sorption of $36 \mathrm{mg} \mathrm{L}^{-1} \mathrm{Cu}(\mathrm{II})$ on $15 \mathrm{~g} \mathrm{~L}^{-1} \mathrm{SSP}$ and $5 \mathrm{~g} \mathrm{~L}^{-1} \mathrm{CFP}$ and $\mathrm{BSP}$ at $5 \mathrm{pH}$ and $\mathrm{RT}$

first and second order adsorption rate constants. In the present case, kinetic data is in good agreement with pseudo second order in terms of coefficient of determination $\left(\mathrm{R}^{2}\right)$ than pseudo first order in all three cases of adsorbents and the adsorption kinetic parameters were given in Table 1. Based on kinetic data, the predicted $\mathrm{q}_{\mathrm{e}}$ values were close to experimental values for pseudo-second-order model. Suitability of pseudo-second-order model suggests chemisorption as the rate limiting step. This chemical adsorption can be explained by the valence forces through sharing electrons between biosorbent (containing $\mathrm{N}$ and $\mathrm{O}$ atoms) and the sorbate ions ${ }^{31}$.

A wide variety of interactions between metal ions and adsorbents like ion exchange, chelation, adsorption by physical forces and entrapment in inter and intra-fibrillar capillaries as well as space of the structural polysaccharide network. As a result, concentration gradient and diffusion are responsible for effective uptake of $\mathrm{Cu}(\mathrm{II})$ in solution and making biosorption as a complex process $^{32}$. Moreover, some non-conventional adsorbents contain cellulose and the polar hydroxyl groups on the cellulose that could be involved in chemical reaction and hence bind heavy metals from solutions ${ }^{33}$. Hence, simple Elovich equation (Eq. 4) was also employed for its applicability on adsorption process (Fig. 5), where, $q_{\mathrm{t}}$ is the amount of $\mathrm{Cu}(\mathrm{II})$ sorbed at a time $\mathrm{t}$, a is the initial copper(II) sorption rate $\left(\mathrm{mg} \mathrm{g}^{-1} \mathrm{~min}^{-1}\right)$ and $b$ is the desorption constant $\left(\mathrm{mg} \mathrm{g}^{-1}\right)$ during any one experiment. Their values were given in Table 2.

$q_{\mathrm{t}}=1 / \mathrm{b} \ln (\mathrm{ab})+1 / \mathrm{b} \ln (\mathrm{t})$

The interactions between adsorbate and adsorbent materials follow film diffusion, pore diffusion and intraparticle transport among which pore diffusion and intraparticle diffusion are often rate-limiting in a batch reactor whereas film diffusion is more likely the rate limiting step for a continuous flow system ${ }^{34}$. Hence, Weber's intra particle diffusion (Eq. 5) model was analyzed and showed reasonably good correlation. The estimated model and the related statistic parameters $\mathrm{K}_{\mathrm{d}}=$ rate constant of the intraparticle transport $\left(\mathrm{mg} \mathrm{g}^{-1} \min ^{1 / 2}\right), \theta=$ constant

Table 1. Pseudo first and second order $\mathrm{Cu}(\mathrm{II})$ adsorption kinetic parameters using BSP, CFP and SSP as biosorbents

\begin{tabular}{|l|c|c|c|c|c|c|c|}
\hline Model & \multicolumn{3}{|c|}{ Pseudo-first-order } & Experimental & \multicolumn{3}{c|}{ Pseudo-second-order } \\
\hline Adsorbent & $\begin{array}{c}\mathrm{q}_{\mathrm{e}} \\
{\left[\mathrm{mg} \mathrm{g}^{-1}\right]}\end{array}$ & $\begin{array}{c}\mathrm{k}_{1} \\
{\left[\mathrm{~min}^{-1}\right]}\end{array}$ & $\mathrm{R}^{2}$ & $\mathrm{q}_{\mathrm{e}}\left[\mathrm{mgg}^{-1}\right]$ & $\mathrm{q}_{\mathrm{e}}\left[\mathrm{mg} \mathrm{g}^{-1}\right]$ & $\mathrm{k}_{2}\left[\mathrm{~g} \mathrm{mg}^{-1} \mathrm{~min}^{-1}\right]$ & $\mathrm{R}^{2}$ \\
\hline BSP & 1.04 & 0.0046 & 0.658 & 6.57 & 7.35 & 0.66 & 0.993 \\
\hline SSP & 1.12 & 0.0207 & 0.924 & 1.89 & 2.11 & 0.20 & 0.999 \\
\hline CFP & 1.02 & 0.0138 & 0.883 & 4.87 & 5.35 & 0.65 & 0.998 \\
\hline
\end{tabular}



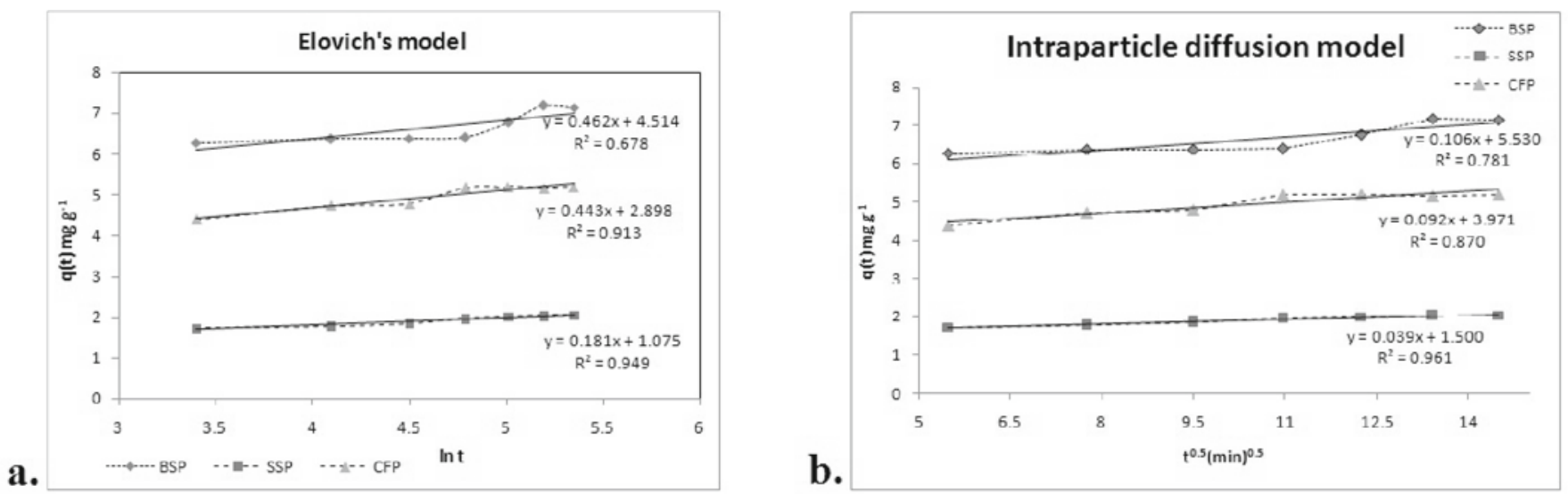

Figure 5. Elovich's and b. Weber's intraparticle diffusion kinetic adsorption models for the sorption of $36 \mathrm{mg} \mathrm{L}^{-1} \mathrm{Cu}_{(\mathrm{II})}$ on $15 \mathrm{~g} \mathrm{~L} \mathrm{~L}^{-1}$ SSP and $5 \mathrm{~g} \mathrm{~L}^{-1} \mathrm{CFP}$ and BSP at $5 \mathrm{pH}$ and $303 \mathrm{~K}$ temperature

Table 2. Weber's intraparticle, Boyd and Elovich's kinetic parameters, of adsorbents, BSP, SSP and CFP

\begin{tabular}{|l|c|c|c|}
\hline \multicolumn{1}{|c|}{ Adsorbent } & BSP & SSP & CFP \\
\hline \multicolumn{3}{|c|}{ Weber's intraparticle diffusion model } \\
\hline $\mathrm{k}_{\mathrm{d}}$ & 0.11 & 0.04 & 0.09 \\
\hline$\theta$ & 5.53 & 1.50 & 3.97 \\
\hline $\mathrm{R}^{2}$ & 0.781 & 0.961 & 0.870 \\
\hline \multicolumn{4}{|c|}{ Boyd model } \\
\hline $\mathrm{R}^{2}$ & 0.862 & 0.927 & 0.850 \\
\hline \multicolumn{4}{|c|}{ Elovich's parameters } \\
\hline $\mathrm{a}[\mathrm{mg} / \mathrm{g} / \mathrm{min}]$ & 8089.91 & 68.72 & 307.22 \\
\hline $1 / \mathrm{b}[\mathrm{mg} / \mathrm{g}]$ & 0.46 & 0.18 & 0.44 \\
\hline $\mathrm{R}^{2}$ & 0.678 & 0.949 & 0.913 \\
\hline
\end{tabular}

related to the thickness of the boundary layer $\left(\mathrm{mg} \mathrm{g}^{-1}\right)$ were reported in Table 2.

$q_{\mathrm{t}}=K_{\mathrm{d}} t^{1 / 2}+\theta$

Information about boundary layer effect can be obtained from a plot of $\mathrm{q}_{\mathrm{t}}$ versus $\mathrm{t}^{0.5}$ (Fig. 5). Higher value of $\theta$ shows that the solute adsorbed by the boundary effect is higher ${ }^{35}$. A linear graph results when intraparticle diffusion is involved in the adsorption process. The process of intraparticle diffusion would be the controlling step if this line passed through the origin. On the other hand, if the line does not pass through the origin then there is some degree of boundary layer control which further shows that intraparticle diffusion is not the only rate-controlling factor, but can be controlled by the other mechanisms. In the present study, Weber's intra particle diffusion linear data not passing through the origin clearly indicates that the existence of pore diffusion process along with intra-particle transport during adsorption. Further, the kinetics data subjected to Boyd kinetics model analysis, $\mathrm{Bt}=-0.4977-\ln (1-\mathrm{F})$ where $\mathrm{F}$ represents the fraction of solute adsorbed at any time, $t(\mathrm{~min})$ revealed the deviation of the metal ions uptake from aqueous system on the adsorbent suggesting that the adsorption mechanism was governed by external mass transport where particle diffusion is the rate limiting step. Though Boyd plot was reasonably linear in case of SSP as adsorbent $\left(R^{2}=0.927\right)$, but has intercept, hence, internal diffusion may not be the sole rate controlling step in the adsorption process ${ }^{36}$.

\section{Effect of adsorbent dose}

The study of varying pattern of adsorption with amount of adsorbent gives the adsorption efficiency of each adsorbent. It was clear from the experimental results
(Fig. 6) that the adsorbent dose can greatly affect the adsorption of $\mathrm{Cu}(\mathrm{II})$ and adsorption increased with increase in adsorbent concentration in reaction mixture due to the availability of more number of active sites on the surface of adsorbent ${ }^{37}$. However, in the case of CFP, percent removal of copper (II) decreased with the increase in adsorbent dosage beyond $10 \mathrm{~g} \mathrm{~L}^{-1}$. This may be due to overlapping of adsorption sites as a result of overcrowding of adsorbent particles in the form of aggregates leading to a reduction in total surface area of adsorbent and increase in diffusion length ${ }^{38}$.

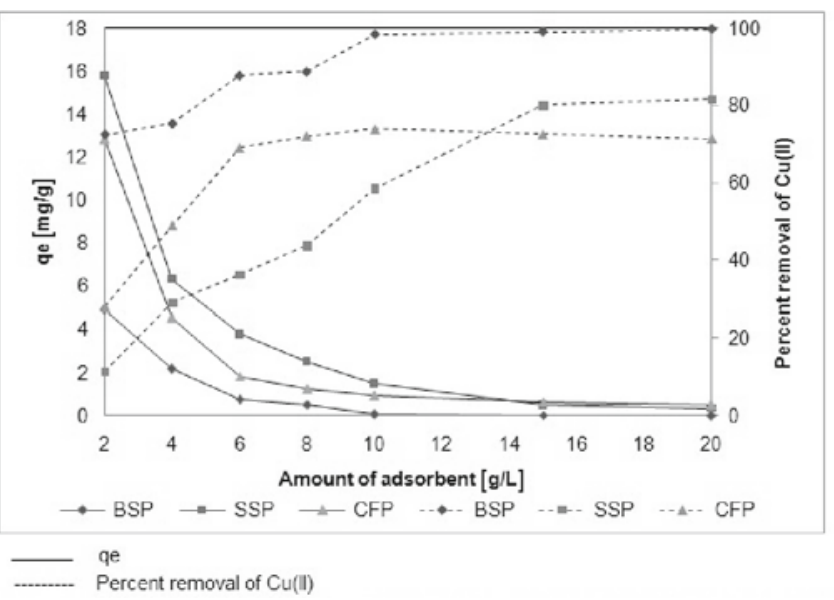

Figure 6. Effect of biosorbent quantity on $\mathrm{Cu}(\mathrm{II})$ uptake by BSP, SSP and CFP at $5 \mathrm{pH}, 36 \mathrm{mg} \mathrm{L}^{-1}$ initial $\mathrm{Cu}$ (II) concentration, $250 \mathrm{rpm}$ and $303 \mathrm{~K}$

\section{Effect of $\mathbf{p H}$}

Solution $\mathrm{pH}$ is critical during adsorption as it governs the adsorption affinity of the adsorbent by affecting surface charge and metal speciation in solution which in turn depends on degree of ionization and the type of adsorbate species. Hence, it was thought of important to study the effect of $\mathrm{pH}$ on the removal of $\mathrm{Cu}(\mathrm{II})$. Patrulea et al. ${ }^{5}$ reported that the protonation of the primary amine groups with positive charge in the acidic media effects the adsorption process by electrostatic repulsion of the cationic $\mathrm{Cu}(\mathrm{II})$ ions present in the medium. According to previously reported findings, precipitation of $\mathrm{Cu}(\mathrm{II})$ ions as copper hydroxides, such as $\mathrm{Cu}(\mathrm{OH})^{+}, \mathrm{Cu}(\mathrm{OH})_{2}$, $\mathrm{Cu}(\mathrm{OH})_{3}{ }^{-}, \mathrm{Cu}(\mathrm{OH})_{4}{ }^{2-}$ occurs at $\mathrm{pH}$ values higher than 5 and beyond this point the adsorption efficiency results could be hampered because of the higher concentration of $\mathrm{OH}^{-}$ions in the medium ${ }^{39}$. In general, a decreasing 
trend in adsorption can be observed after $\mathrm{pH} 7$ due to the formation of the copper hydroxyl precipitates and soluble hydroxy complexes ${ }^{11}, 40$. Therefore, the effect of $\mathrm{pH}$ on adsorption using BSP, SSP and CFP was studied in the initial $\mathrm{pH}$ range of 2 to 5 in solution. It is reported in the literature that the uptake of $\mathrm{Cu}(\mathrm{II})$ increases with increase in $\mathrm{pH}$ in acidic medium and is predominantly removed in the $\mathrm{pH}$ vicinity of $5^{26,41}$. Similar pattern of increasing adsorption percentage with increase in $\mathrm{pH}$ was observed from 2 to 5 (Fig. 7). In particular, the sorption of $\mathrm{Cu}(\mathrm{II})$ increased slowly in the $\mathrm{pH}$ range 2 to 4 , stabilized at $\mathrm{pH} 4$ to 5 in all three cases of adsorbents. As explained previously, the lower adsorption rate at lower $\mathrm{pH}$ values is due to the higher concentration of $\mathrm{H}^{+}$ions present in the reaction mixture inducing repulsive forces, between $\mathrm{Cu}$ (II) ions for the adsorption sites of biosorbents where the adsorbent surface acquired a positive charges and hence the repulsive forces ${ }^{41}$. In addition, an increase in removal with an increase in $\mathrm{pH}$ can be attributed to the release of $\mathrm{H}^{+}$ions from the sorbent sites which help in increase of electrostatic attraction force between the active surface and $\mathrm{Cu}(\mathrm{II})$ ions where the negative charged carboxylic/phenolic surface provides affinity site for the uptake of divalent copper ions.

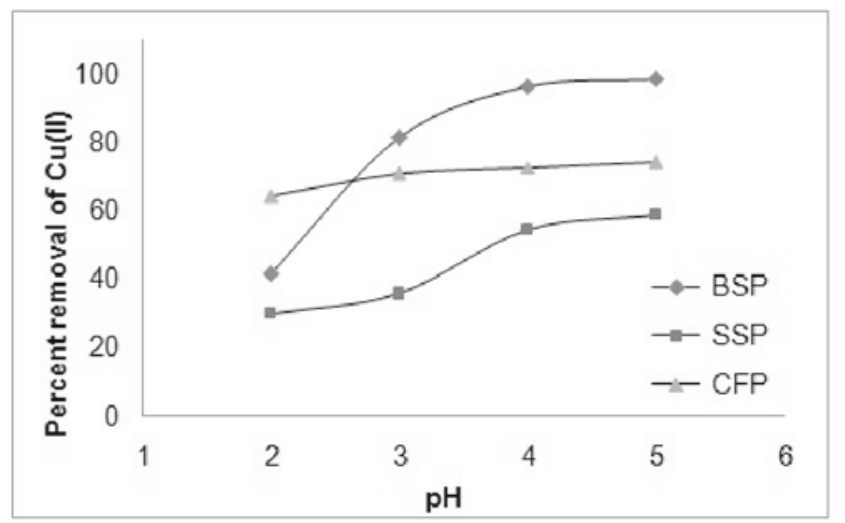

Figure 7. Effect of $\mathrm{pH}$ on $\mathrm{Cu}$ (II) uptake using $10 \mathrm{~g} \mathrm{~L}^{-1}$ BSP, SSP and $\mathrm{CFP}$ at $303 \mathrm{~K}, 36 \mathrm{mg} \mathrm{L}^{-1}$ initial $\mathrm{Cu}(\mathrm{II})$ concentration, $250 \mathrm{rpm}$ agitation speed

\section{Effect of temperature}

The adsorption percentage increased with an increase in temperature in case of SSP and CFP, whereas, in case of BSP, the adsorption percentage did not significantly change with increasing temperature (Fig. 8). The enhanced metal sorption capacity of CFP and SSP with an increase in temperature may be attributed to the rise in the kinetic energy / mobility of metal ions from the bulk solution towards the adsorbent surface leading to an increase in collision frequency between sorbent and sorbate as well as extent of penetration within biosorbent structure overcoming the rate of intraparticle diffusion ${ }^{42,43}$. Additionally, at high temperature, there

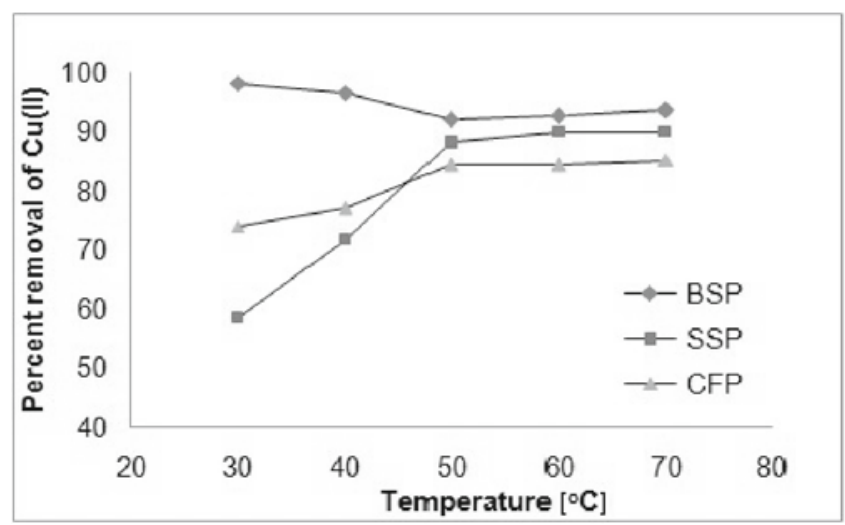

Figure 8. Effect of temperature on $\mathrm{Cu}(\mathrm{II})$ uptake by $20 \mathrm{~g} \mathrm{~L}^{-1} \mathrm{BSP}$, $\mathrm{SSP}$ and CFP at $5 \mathrm{pH}, 36 \mathrm{mg} \mathrm{L}^{-1}$ initial $\mathrm{Cu}$ (II) concentration and $250 \mathrm{rpm}$ agitation speed

may be an enlargement of pore size of biosorbents and increase in number of active sorption sites due to bond rupture of functional groups on adsorbent ${ }^{44}$. However, in case of BSP as adsorbent, a slight decrease in the adsorption percentage with an increase in temperature was observed (Fig. 8). This observation can be explained based on (i) increased escaping tendency of already adsorbed molecules from adsorbent into the bulk solution due to increase in total energy of sorbate molecules at higher temperature ${ }^{\mathbf{4 5}}$ and (ii) dissolution of sorbing solution because adsorbent functional groups are soluble at high temperatures ${ }^{46}$. Though, this seems to be corroborates with the well-known fact that sorption capacity is expected to decrease with an increase in solution temperature when sorption process is exothermic, the present case involves both physical and chemical adsorptions and such simultaneous occurrence of both adsorptions was reported earlier by Ho et al. McKay ${ }^{47}$ and Panday et al. ${ }^{48}$. Thermodynamic parameters calculated as a function of temperature were presented in Table 3. The positive value of $\boldsymbol{\Delta} \mathbf{S}$ reflects the affinity of the adsorbent for the adsorbate and suggests some structural changes in both of them. In addition, positive value of $\mathbf{\Delta S}$ may show the increasing randomness at the solid/liquid interface during the adsorption. $\mathbf{\Delta S}$ value is zero when the entire process is reversible. The negative $\mathbf{\Delta} \mathbf{S}$ value indicated the decrease in the randomness of the system and the adsorption process is not irreversible ${ }^{49}$.

\section{Effect of initial $\mathbf{C u}(\mathrm{II})$ concentration}

Initial metal concentration of the solution is the driving force to overcome all the mass transfer resistances of the metal between aqueous and solid phase and hence a higher initial concentration of metal ions may increase the adsorption capacity ${ }^{1}$. Incompletion of adsorption sites during adsorption reaction and the aggregation of adsorbent particles at higher concentration are the important factors which contribute to the adsorbate con-

Table 3. Thermodynamic parameters for the adsorption of $\mathrm{Cu}(\mathrm{II})$ onto $10 \mathrm{~g} \mathrm{~L}^{-1}$ of BSP, SSP and CFP at $5 \mathrm{pH}, 35 \mathrm{mg} \mathrm{L} \mathrm{initial}^{-1}$ $\mathrm{Cu}$ (II) concentration and $250 \mathrm{rpm}$ agitation speed

\begin{tabular}{|c|c|c|c|c|c|c|}
\hline \multirow{2}{*}{$\mathrm{T}[\mathrm{K}]$} & \multicolumn{3}{|c|}{$\Delta \mathrm{G}[\mathrm{kJ} / \mathrm{mol}]$} & \multicolumn{3}{|c|}{$\Delta \mathrm{H}[\mathrm{kJ} / \mathrm{mol}]$} \\
\hline & BSP & SSP & CFP & BSP & SSP & CFP \\
\hline 303 & -9.54 & -1.30 & -2.76 & -31.01 & 43.44 & 16.41 \\
\hline 313 & -8.83 & -2.78 & -3.40 & & & \\
\hline 333 & -7.41 & -5.73 & -4.66 & BSP & SSP & CFP \\
\hline 343 & -6.70 & -7.21 & -5.30 & -0.07 & 0.15 & 0.06 \\
\hline
\end{tabular}


centration effect. Figure 9 shows the effect of metal ion concentration on its removal from the aqueous solution for adsorbent materials. On changing the initial concentration of $\mathrm{Cu}(\mathrm{II})$ from 35 to $200 \mathrm{mg} \mathrm{L}^{-1}$, the amount adsorbed increased from 1.75 to $6.10 \mathrm{mg} \mathrm{g}^{-1}$ in case of BSP, 1.42 to $5.92 \mathrm{mg} \mathrm{g}^{-1}$ in case of SSP and 1.24 to $3.73 \mathrm{mg} \mathrm{g}^{-1}$ in case of CFP as adsorbent. A continuous decline of percentage removal with increase in metal ion concentration was observed. This appears to be due to increase in number of metal ions competing for the available binding sites in the biomass and also due to the lack of binding sites for the attachment of $\mathrm{Cu}$ (II) ions at higher concentration levels ${ }^{11}$.

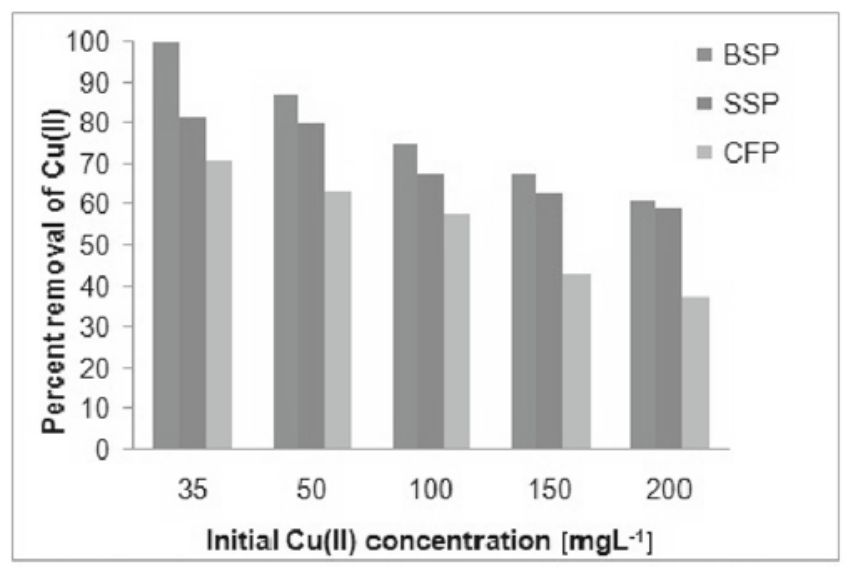

Figure 9. Effect of initial $\mathrm{Cu}(\mathrm{II})$ concentration in solution on adsorption of $\mathrm{Cu}$ (II) using $20 \mathrm{~g} \mathrm{~L}^{-1} \mathrm{BSP}$, SSP and CFP at $5 \mathrm{pH}, 250 \mathrm{rpm}$ and $303 \mathrm{~K}$

\section{Adsorption isotherms}

Adsorption isotherms are significant in describing the mechanism of adsorption for analyzing the interaction of metal ion on the surface of adsorbent. Figures 10a and $10 \mathrm{~b}$ described the Langmuir and Freundlich adsorption isotherms respectively for $\mathrm{Cu}(\mathrm{II})$ removal using BSP, SSP and CFP. The values of characteristic parameters
Langmuir, Freundlich, D-R and Temkin models were given in Table 4 . The Temkin isotherm equation explicitly takes into the account of adsorbent-adsorbate interactions by ignoring the extremely low and large value of concentrations. It assumes that the heat of adsorption of all the molecules in layer decreases linearly rather than logarithmic with coverage due to adsorbent-adsorbate interactions ${ }^{50}$. The best fitting order of these models is concluded to be

Freundlich $>$ Temkin $>$ Langmuir $>$ D-R $\quad$ : for BSP and SSP

Langmuir $>$ Temkin $>$ D-R $>$ Freundlich : for CFP

Langmuir isotherm model fitted the results quite well for removal of copper ions by CFP (Table 4) suggesting that (a) the surface of the sorbent is homogenous, (b) all sites are energetically equivalent and each binding site accepts only one $\mathrm{Cu}$ (II) molecule, (c) the sorbed molecules are organized as a monolayer and (d) no interaction between sorbed molecules. Similar observations were reported in the $\mathrm{Cu}$ (II) removal by saw dust $^{1}$, fish bones ${ }^{27}$ and chitosan ${ }^{5}$. Table 4 showed that the best correlation of the experimental results was obtained with the Freundlich isotherm model with BSP and SSP and it also confirmed favorable from $1 / \mathrm{n}$ values $<1$. This suggests that $\mathrm{Cu}(\mathrm{II})$ ions were adsorbed onto these adsorbent surfaces in different ways. DubininRadushkevich (D-R) isotherm can be generally applied to express the adsorption mechanism with a Gaussian energy distribution onto a heterogeneous surface ${ }^{51}$. The approach was usually applied to distinguish the physical and chemical adsorption of metal ions with its mean free energy. Compared to other adsorbents, D-R isotherm fitted well to CFP. Table 5 described the favorable shape factor values which were between 0 to 1 determined from the Langmuir isotherms for all three cases of adsorbents (BSP, SSP and CFP) at different initial $\mathrm{Cu}(\mathrm{II})$ concentrations ${ }^{47}$.

Table 4. Copper (II) biosorption isotherm parameters i.e. Langmuir, Freundlich, D.R. and Temkin models by $20 \mathrm{~g}^{-1}$ of adsorbents, BSP, SSP and CFP at $5 \mathrm{pH}, 303 \mathrm{~K}$ and $250 \mathrm{rpm}$ agitation speed

\begin{tabular}{|c|c|c|c|c|c|c|c|c|c|c|c|c|}
\hline \multirow[b]{2}{*}{ Adsorbent } & \multicolumn{3}{|c|}{ Langmuir Isotherm } & \multicolumn{3}{|c|}{ Freundlich Isotherm } & \multicolumn{3}{|c|}{ D-R Isotherm } & \multicolumn{3}{|c|}{ Temkin Isotherm } \\
\hline & $\mathrm{K}_{\mathrm{L}}[\mathrm{L} / \mathrm{mg}]$ & $\mathrm{q}_{\mathrm{m}}[\mathrm{mg} / \mathrm{g}]$ & $\mathrm{R}^{2}$ & $\begin{array}{c}\mathrm{K}_{\mathrm{F}} \\
{\left[(\mathrm{mg} / \mathrm{g})(\mathrm{L} / \mathrm{mg})^{1 / n}\right]}\end{array}$ & $1 / n$ & $\mathrm{R}^{2}$ & $\mathrm{~B}_{\mathrm{D}}$ & $\mathrm{q}_{\mathrm{D}}[\mathrm{mol} / \mathrm{g}]$ & $\mathrm{R}^{2}$ & B & $A_{T}$ & $\mathrm{R}^{2}$ \\
\hline BSP & 0.100 & 6.494 & 0.949 & 0.989 & 0.417 & 0.999 & $1 \times 10^{-8}$ & 3.327 & 0.862 & 1.552 & 4.721 & 0.973 \\
\hline SSP & 0.029 & 7.937 & 0.956 & 0.537 & 0.540 & 0.993 & $8 \times 10^{-7}$ & 2.291 & 0.840 & 1.675 & 5.339 & 0.961 \\
\hline CFP & 0.034 & 4.545 & 0.990 & 0.451 & 0.449 & 0.957 & $1 \times 10^{-7}$ & 2.565 & 0.959 & 1.014 & 2.757 & 0.972 \\
\hline
\end{tabular}
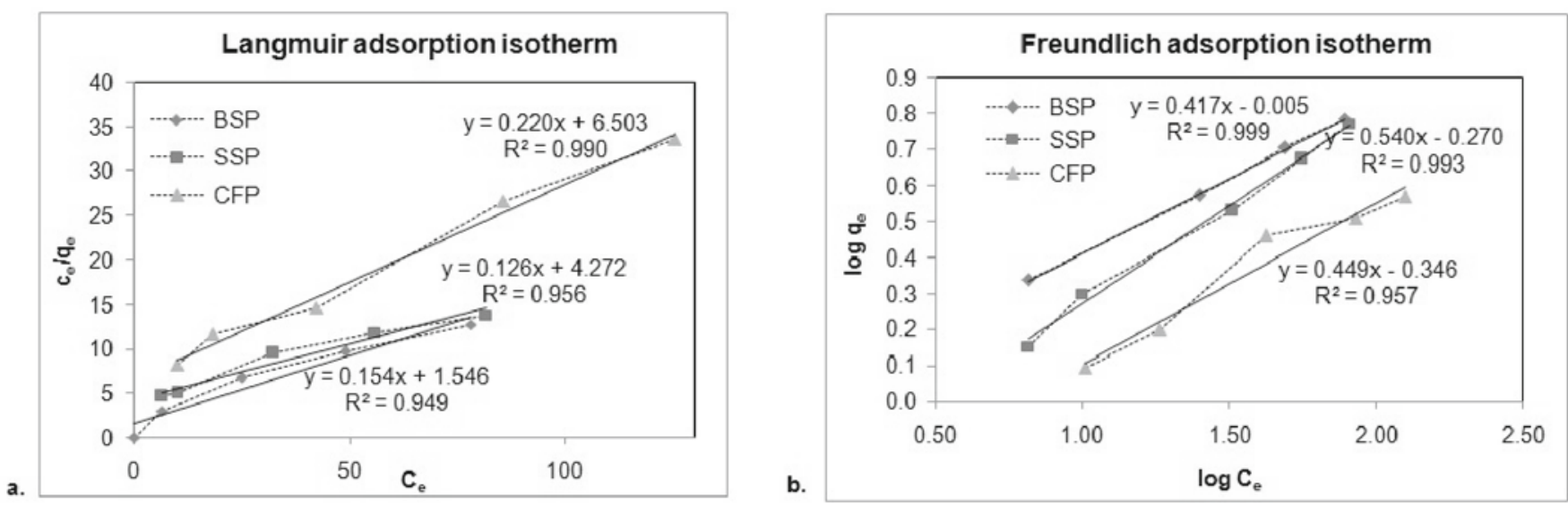

Figure 10. Linear adsorption isotherm plots for a. Langmuir's model and b. Freudlich's model on Cu(II) uptake by BSP, SSP and CFP at 5 pH, $250 \mathrm{rpm}$ agitation speed and $303 \mathrm{~K}$ temperature 
Table 5. The shape factor Langmuir parameter, RL values for $\mathrm{Cu}$ (II) uptake by adsorbents, BSP, SSP and CFP

\begin{tabular}{|c|c|c|c|}
\hline \multicolumn{4}{|c|}{$\mathrm{R}_{\mathrm{L}}$} \\
\hline $\mathrm{C}_{\mathrm{o}}\left[\mathrm{mg} \mathrm{L}^{-1}\right]$ & $\mathrm{BSP}$ & $\mathrm{SSP}$ & $\mathrm{CFP}$ \\
\hline 50 & 0.167 & 0.408 & 0.370 \\
\hline 100 & 0.091 & 0.256 & 0.227 \\
\hline 150 & 0.063 & 0.187 & 0.164 \\
\hline 200 & 0.048 & 0.147 & 0.128 \\
\hline
\end{tabular}

A comparison of the copper ions uptake capacities of BSP, CFP and SSP with other biomaterial based sorbents is presented in Table 6. However, a direct comparison may not be possible due to a variety of parameters and conditions employed in each referenced work. In spite of lower removal capacity of these adsorbents, considering the fact that these three adsorbents are abundantly available, the efficient $\mathrm{Cu}$ (II) removal from industrial wastewater could be achieved by utilizing these waste materials as adsorbents in large quantities.

Table 6. Comparison of maximum adsorption capacities of various adsorbents for $\mathrm{Cu}(\mathrm{II})$ ions

\begin{tabular}{|c|c|}
\hline Adsorbents & $q_{m}\left[\mathrm{mg} \mathrm{g}^{-1}\right]$ \\
\hline Pretreated black tea waste ${ }^{11}$ & 43.1 \\
\hline Pretreated fish bones ${ }^{27}$ & 102.9 \\
\hline Grapeseed activated carbon ${ }^{39}$ & 48.8 \\
\hline Chestnut shell activated carbon ${ }^{39}$ & 100.0 \\
\hline Mushroom biomass ${ }^{52}$ & 9.1 \\
\hline Pineapple leaf powder ${ }^{53}$ & 9.3 \\
\hline Spent activated clay ${ }^{54}$ & 10.9 \\
\hline Calcium alginate immobilized $\mathrm{cnts}^{55}$ & 84.9 \\
\hline Banana bunchstem powder (This study) & 6.5 \\
\hline Sorghum stem powder (This study) & 7.9 \\
\hline Casuarinas fruit powder (This study) & 4.5 \\
\hline
\end{tabular}

\section{CONCLUSIONS}

The maximum adsorption efficiencies of the three adsorbents for $\mathrm{Cu}$ (II) removal from aqueous solutions were $6.5,7.9$ and $4.5 \mathrm{mg} \mathrm{L}^{-1}$ using BSP, SSP and CFP respectively and can be correlated with their microporous structures, where, rough surface with some cavities for all three adsorbents indicating high possibility of adsorption. It is evident from the kinetic data that the chemosorption is the possible adsorption mechanism involved in $\mathrm{Cu}(\mathrm{II})$ removal using $\mathrm{BSP}$ and $\mathrm{CFP}$ as adsorbents, whereas, a combination of both physisorption and chemical attachment involved when SSP was used as an adsorbent. Adsorption isotherm studies describe that both mono and multilayer adsorptions occur in the present studies with preference to monolayer adsorption in case of CFP and multilayer adsorption in case of BSP and SSP. Presented results affirmed suitability of low-cost, adsorbents (BSP, SSP and CFP) for copper removal from aqueous environment.

\section{ACKNOWLEDGEMENT}

The authors are highly thankful to Acharya Nagarjuna University for providing the support for conducting the research work. Authors are also wish to thank SAIF, IIT, Madras for providing SEM-EDX instrumentation facility.

\section{LITERATURE CITED}

1. Larous, S. \& Meniai, A.H. (2012). Removal of copper (II) from aqueous solution by agricultural by-products-sawdust. Ener. Proc. 18, 915-923. DOI: 10.1016/j.egypro.2012.05.106.

2. Rozaini, C.A., Jain, K., Oo, C.W., Tan, K.W., Tan, L.S., Azraa, A. \& Tong, K.S. (2010). Optimization of nickel and copper ions removal by modified mangrove barks. Int. J. Chem. Eng. Appl. 1(1), 84-89. DOI: 10.7763/IJCEA.2010.V1.14.

3. WHO, World Health Organization (2004). Guidelines for Drinking-water Quality, third ed., Recommendations, Geneva. 4. Manzoor, Q., Nadeem, R., Iqbal, M., Saeed, R. \& Ansari, T.M. (2013). Organic acids pretreatment effect on Rosa bourbonia phyto-biomass for removal of $\mathrm{Pb}$ (II) and $\mathrm{Cu}$ (II) from aqueous media. Biores. Technol. 132, 446-452. DOI: 10.1016/j. biortech.2013.01.156.

5. Patrulea, V., Negrulescu, A., Mincea, M., Pitulice, L., Spiridon, O. \& Ostafe, V. (2013). Optimization of the removal of copper(ii) ions from aqueous solution on chitosan and cross-linked chitosan beads. BioResources. 8. DOI: 10.15376/ biores.8.1.1147-1165.

6. Acar, F.N. \& Eren, Z. (2006). Removal of $\mathrm{Cu}(\mathrm{II})$ ions by activated poplar sawdust (Samsun Clone) from aqueous solutions. J. Hazard. Mater. 137(2), 909-914. DOI: 10.1016/j. jhazmat.2006.03.014.

7. Ramya, P.M., Venkata, N.R., Jayasravanthi, M. \& Dulla, B.J. (2015). Chemical oxygen demand reduction from coffee processing waste water-A comparative study on usage of biosorbents prepared from agricultural wastes, Global NEST J. 17(2), 291-300.

8. Cestari, A.R., Vieira, E.F., de Oliveira, I.A. \& Bruns, R.E. (2007). The removal of $\mathrm{Cu}(\mathrm{II})$ and $\mathrm{Co}(\mathrm{II})$ from aqueous solutions using cross-linked chitosan--evaluation by the factorial design methodology, J. Hazard. Mater. 143(1-2), 8-16. DOI: 10.1016/j.jhazmat.2006.08.063.

9. Lima, I.S., Lazarin, A.M. \& Airoldi, C. (2005). Favorable chitosan/cellulose film combinations for copper removal from aqueous solutions. Int. J. Biol. Macromol. 36(1), 79-83. DOI: 10.1016/j.ijbiomac.2005.04.001.

10. Jamnongkan, T., Kantarot, K., Niemtang, K., Pansila, P.P. \& Wattanakornsiri, A. (2014). Kinetics and mechanism of adsorptive removal of copper from aqueous solution with poly (vinyl alcohol) hydrogel. Trans. Nonfer. Met. Soc. China 24(10), 3386-3393. DOI: 10.1016/S1003-6326(14)63481-6.

11. Weng, C.H., Lin, Y.T., Hong, D.Y., Sharma, Y.C., Chen, S.C. \& Tripathi, K. (2014). Effective removal of copper ions from aqueous solution using base treated black tea waste. Ecol. Eng. 67, 127-133. DOI: 10.1016/j.ecoleng.2014.03.053.

12. Vieira, M.G.A., de Almeida Neto, A.F., da Silva, M.G.C., Carneiro, C.N. \& Melo Filho, A.A. (2014). Adsorption of lead and copper ions from aqueous effluents on rice husk ash in a dynamic system. Braz. J. Chem. Eng. 31(2), 519-529. DOI: 10.1590/0104-6632.20140312s00002103.

13. Hossain, M.A., Ngo, H.H., Guo, W.S. \& Setiadi, T. (2012). Adsorption and desorption of copper (II) ions onto garden grass. Biores. Technol. 121, 386-395. DOI: 10.1016/j. biortech.2012.06.119.

14. Liang, S., Guo, X., Feng, N. \& Tian, Q. (2010). Isotherms, kinetics and thermodynamic studies of adsorption of $\mathrm{Cu}^{2+}$ from aqueous solutions by $\mathrm{Mg}^{2+} / \mathrm{K}^{+}$type orange peel adsorbents. J. Hazard. Mater. 174(1), 756-762. DOI: 10.1016/j. jhazmat.2009.09.116.

15. Bilal, M., Shah, J.A., Ashfaq, T., Gardazi, S.M.H., Tahir, A.A., Pervez, A. \& Mahmood, Q. (2013). Waste biomass adsorbents for copper removal from industrial wastewater-A review. J. Hazard. Mater. 263, 322-333. DOI: 10.1016/j. jhazmat.2013.07.071.

16. Chen, J.P. \& Yang, L. (2005). Chemical modification of Sargassum sp. for prevention of organic leaching and enhan- 
cement of uptake during metal biosorption. Ind. Eng. Chem. Res. 44(26), 9931-9942. DOI: 10.1021/ie050678t.

17. Li, Y., Xia, B., Zhao, Q., Liu, F., Zhang, P., Du, Q. \& Xia, Y. (2011). Removal of copper ions from aqueous solution by calcium alginate immobilized kaolin. J. Env. Sci. 23(3), 404-411. DOI: 10.1016/S1001-0742(10)60442-1.

18. Xue, Y., Gao, B., Yao, Y., Inyang, M., Zhang, M., Zimmerman, A.R. \& Ro, K.S. (2012). Hydrogen peroxide modification enhances the ability of biochar (hydrochar) produced from hydrothermal carbonization of peanut hull to remove aqueous heavy metals: batch and column tests. Chem. Eng. J. 200, 673-680. DOI: 10.1016/j.cej.2012.06.116.

19. Annual book of ASTM standards part - 23, (1972). Am. Soc. Test. Mater. Philadelphia.

20. Gong, J.L., Wang, X.Y., Zeng, G.M., Chen, L., Deng, J.H., Zhang, X.R. \& Niu, Q.Y. (2012). Copper (II) removal by pectin-iron oxide magnetic nanocomposite adsorbent. Chem. Eng. J. 185, 100-107. DOI: 10.1016/j.cej.2012.01.050.

21. Li, K., Fu, S., Zhan, H., Zhan, Y. \& Lucia, L. (2010). Analysis of the chemical composition and morphological structure of banana pseudo-stem. Bioresources 5(2), 576-585. DOI: $10.15376 /$ biores.5.2.576-585

22. Firdous, R. \& Gilani, A.H. (2001). Changes in chemical composition of sorghum as influenced by growth stages and cultivar. Asian Australas. J. Anim. Sci. 14(7), 935-940. DOI: http://dx.doi.org/10.5713/ajas.2001.935.

23. Ogunwande, I.A., Flamini, G., Adefuye, A.E., Lawal, N.O., Moradeyo, S. \& Avoseh, N.O. (2011). Chemical compositions of Casuarina equisetifolia L., Eucalyptus toreliana L. and Ficus elastica Roxb. ex Hornem cultivated in Nigeria. S. Afr. J. Bot. 77(3), 645-649. DOI: 10.1016/j.sajb.2011.02.001.

24. Lerivrey, J., Dubois, B., Decock, P., Micera, G., Urbanska, J. \& Kozłowski, H. (1986). Formation of D-glucosamine complexes with $\mathrm{Cu}$ (II), Ni (II) and Co (II) ions. Inorg. Chim. Acta 125(4), 187-190. DOI: 10.1016/S0020-1693(00)81209-8.

25. Mahaninia, M.H., Rahimian, P. \& Kaghazchi, T. (2015). Modified activated carbons with amino groups and their copper adsorption properties in aqueous solution. Chin. J. Chem. Eng. 23(1), 50-56. DOI: 10.1016/j.cjche.2014.11.004.

26. Sarioglu, M., Atay, Ü.A. \& Cebeci, Y. (2005). Removal of copper from aqueous solutions by phosphate rock. Desalination 181(1), 303-311. DOI: 10.1016/j.desal.2005.04.009.

27. Kizilkaya, B., Tekinay, A.A. \& Dilgin, Y. (2010). Adsorption and removal of $\mathrm{Cu}$ (II) ions from aqueous solution using pretreated fish bones. Desalination 264(1), 37-47. DOI: 10.1016/j. desal.2010.06.076.

28. Ge, Y., Cui, X., Kong, Y., Li, Z., He, Y. \& Zhou, Q. (2015). Porous geopolymeric spheres for removal of $\mathrm{Cu}$ (II) from aqueous solution: Synthesis and evaluation. J. Hazard. Mater. 283, 244-251. DOI: 10.1016/j.jhazmat.2014.09.038.

29. Lagergren, S. (1898). On the theory of so-called adsorption solutes, The Royal Swedish Academy of Sciences. Handlingar 24(4), 1-39 (in German).

30. Ho, Y.S. \& McKay, G. (1999). Pseudo-second order model for sorption processes. Process Biochem. 34(5), 451-465. DOI: 10.1016/S0032-9592(98)00112-5.

31. Ho, Y.S. \& McKay, G. (2000). The kinetics of sorption of divalent metal ions onto sphagnum moss peat. Water Res. 34(3), 735-742. DOI: 10.1016/S0043-1354(99)00232-8.

32. Ahluwalia, S.S. \& Goyal, D. (2007). Microbial and plant derived biomass for removal of heavy metals from wastewater. Biores. Technol. 98(12), 2243-2257. DOI:10.1016/j. biortech.2005.12.006.

33. Igwe, J.C. \& Abia, A.A. (2005). Competitive adsorption of $\mathrm{Zn}$ (II), Cd (II) and $\mathrm{Pb}$ (II) ions from aqueous and nonaqueous solution by maize cob and husk. Afr. J. Biotechnol. 4(10), 1113-1116. DOI: 10.5897/AJB2005.000-3220.

34. Goswami, S. \& Ghosh, U.C. (2006). Studies on adsorption behaviour of $\mathrm{Cr}$ (VI) onto synthetic hydrous stannic oxide. Water SA, 31(4), 597-602. http://dx.doi.org/10.4314/wsa.v31i4.5150
35. Greluk, M. \& Hubicki, Z. (2009). Sorption of SPADNS azo dye on polystyrene anion exchangers: equilibrium and kinetic studies. J. Hazard. Mater. 172(1), 289-297. DOI: 10.1016/j. jhazmat.2009.07.007.

36. Kumar, P. S., Ramalingam, S., Kirupha, S.D., Murugesan, A., Vidhyadevi, T. \& Sivanesan, S. (2011). Adsorption behavior of nickel (II) onto cashew nut shell: Equilibrium, thermodynamics, kinetics, mechanism and process design. Chem. Eng. J. 167(1), 122-131. DOI: 10.1016/j.cej.2010.12.010.

37. Garg, U.K., Kaur, M.P., Garg, V.K. \& Sud, D. (2007). Removal of hexavalent chromium from aqueous solution by agricultural waste biomass. J. Hazard. Mater. 140(1), 60-68. DOI: 10.1016/j.jhazmat.2006.06.056.

38. Chang, Y., Liu, H., Zha, F., Chen, H., Ren, X. \& Lei, Z. (2011). Adsorption of $\mathrm{Pb}$ (II) by N-methylimidazole modified palygorskite. Chem. Eng. J. 167(1), 183-189. DOI: 10.1016/j. cej.2010.10.081.

39. Özçimen, D. \& Ersoy-Meriçboyu, A. (2009). Removal of copper from aqueous solutions by adsorption onto chestnut shell and grape seed activated carbons. J. Hazard. Mater. 168(2), 1118-1125. DOI: 10.1016/j.jhazmat.2009.02.148.

40. Krishnan, K.A. \& Anirudhan, T.S. (2003). Removal of cadmium (II) from aqueous solutions by steam-activated sulphurised carbon prepared from sugar-cane bagasse pith: Kinetics and equilibrium studies. Water SA, 29(2), 147-156. http://dx.doi.org/10.4314/wsa.v29i2.4849

41. Zheng, W., Li, X. M., Wang, F., Yang, Q., Deng, P. \& Zeng, G.M. (2008). Adsorption removal of cadmium and copper from aqueous solution by areca-a food waste. J. Hazard. Mater. 157(2), 490-495. DOI: 10.1016/j.jhazmat.2008.01.029.

42. Kumar, U. (2011). Thermodynamics of the Adsorption of Cd (II) from Aqueous Solution on NCRH. I. Jesd. 2(5), 334-336. DOI: 10.7763/IJESD.2011.V2.147.

43. Agrawal, A., Sahu, K.K. \& Pandey, B.D. (2004). Removal of zinc from aqueous solutions using sea nodule residue. Coll. Surf. A. 237(1), 133-140. DOI: 10.1016/j.colsurfa.2004.01.034. 44. Tewari, N., Vasudevan, P. \& Guha, B.K. (2005). Study on biosorption of $\mathrm{Cr}$ (VI) by Mucor hiemalis. Biochem. Eng. J. 23(2), 185-192. DOI: 10.1016/j.bej.2005.01.011.

45. Sharma, Y.C., Prasad, G. \& Rupainwar, D.C. (1991). Removal of Ni (II) from aqueous solutions by sorption. Int. J. Environ. Stud. 37(3), 183-191. DOI: 10.1080/00207239108710629. 46. Dai, J. \& Mumper, R.J. (2010). Plant phenolics: extraction, analysis and their antioxidant and anticancer properties. Molecules 15(10), 7313-7352. DOI: 10.3390/molecules15107313. 47. Ho, Y.S., Porter, J.F. \& McKay, G. (2002). Equilibrium isotherm studies for the sorption of divalent metal ions onto peat: copper, nickel and lead single component systems. Water Air Soil Poll. 141(1-4), 1-33. DOI: 10.1023/A:1021304828010. 48. Panday, K.K., Prasad, G. \& Singh, V.N. (1984). Removal of $\mathrm{Cr}$ (V1) from aqueous solutions by adsorption on fly ash-wollastonite. J. Chem. Technol. Biotechnol. 34(7), 367-374. DOI: $10.1002 /$ jctb.5040340703.

49. Varank, G., Demir, A., Yetilmezsoy, K., Top, S., Sekman, E. \& Sinan Bilgili, M. (2012). Removal of 4-nitrophenol from aqueous solution by natural low-cost adsorbents. Indian $J$. Chem. Technol. 19(1), 7-25.

50. Temkin, M.I. \& Pyzhev, V. (1940). Kinetics of ammonia synthesis on promoted iron catalysts. Acta Physio. Chim. URSS, 12(3), 217-222.

51. Dąbrowski, A. (2001). Adsorption-from theory to practice. Adv. Coll. Interface. Sci. 93(1), 135-224. DOI: 10.1016/S00018686(00)00082-8.

52. Ertugay, N. \& Bayhan, Y.K. (2010). The removal of copper (II) ion by using mushroom biomass (Agaricus bisporus) and kinetic modeling. Desalination 255, 137-142. DOI: 10.1016/j. desal.2010.01.002.

53. Weng, C.H. \& Wu, Y.C. (2012). Potential low-cost biosorbent for copper removal:pineapple leaf powder. J. Environ. 
Eng.-ASCE 138, 286-292. http://dx.doi.org/10.1061/(ASCE) EE.1943-7870.0000424

54. Weng, C.H., Tsai, C.Z., Chu, S.H. \& Sharma, Y.C. (2007). Adsorption characteristics ofcopper(II) onto spent activated clay. Sep. Purif. Technol. 54, 187-197. DOI: 10.1016/j.seppur.2006.09.009.

55. Li, Y., Liu, F., Xia, B., Du, Q., Zhang, P., Wang, D., Wang, Z. \& Xia, Y. (2010). Removal ofcopper from aqueous solution by carbon nanotube/calcium alginate composites. J. Hazard. Mater. 177, 876-880. DOI: 10.1016/j.jhazmat.2009.12.114. 